Research Article

\title{
Experimental Study on Fragmentation Behavior of Specimen with Rockbolts
}

\author{
Enyuan Dong $\mathbb{D}^{1},{ }^{1}$ Weijun Wang $\mathbb{D}^{2,3}$ Zhiwei Zhao, ${ }^{4}$ Wenqing Peng, ${ }^{2}$ and Chao Yuan $\mathbb{D}^{2}$ \\ ${ }^{1}$ School of Mining and Geomatics Engineering, Hebei University of Engineering, Handan 056038, China \\ ${ }^{2}$ School of Resource Environment and Safety Engineering, Hunan University of Science and Technology, Xiangtan 411201, China \\ ${ }^{3}$ Hunan Provincial Key Laboratory of Safe Mining Techniques of Coal Mines, Hunan University of Science and Technology, \\ Xiangtan 411201, China \\ ${ }^{4}$ Guangxi Road and Bridge Engineering Group Co., Ltd., Nanning 530011, China
}

Correspondence should be addressed to Weijun Wang; wjwang@hnust.edu.cn

Received 29 November 2019; Revised 21 September 2020; Accepted 15 October 2020; Published 31 October 2020

Academic Editor: Fan Gu

Copyright (C) 2020 Enyuan Dong et al. This is an open access article distributed under the Creative Commons Attribution License, which permits unrestricted use, distribution, and reproduction in any medium, provided the original work is properly cited.

The effect of rockbolt density on fractured specimens and the distribution law of fragments were studied using the fractal method. The results show that with the increase of rockbolt density, the strength of specimens is improved. Its degree of fragmentation is increased, but the average size of fragments is decreased. The fragmentation and surface fractal dimensions are increased, their difference value is 1 in theory, but the value is slightly less than 1 in practical application due to the uncertain factors such as anisotropy of specimen. There is a positive correlation between the deformation of surrounding rock and its fractal dimension. The surface fractal dimension of surrounding rock can give a quantitative description of its degree of fragmentation and can give a comprehensive reflection to the roof stability. The support mechanism of rockblots can be understood as improving the probability of refragmentation of fragments, making its distribution gradation close to the optimal one with minimum porosity, thus reducing the deformation of surrounding rock.

\section{Introduction}

The plastic zone, in which the surrounding rock is loosened and fractured, is formed due to unloading after underground excavation. The deformation of surrounding rock is caused by the dilatancy of fragments, which is the root of the passive bearing of the support system. And the deformation accompanied by dilatancy is also the main objective of support in mining engineering [1-4]. It will play a very important role in understanding the effect of rockbolts and evaluating the stability of roadway to study the support mechanism of rockbolts on the fractured surrounding rock.

Deformation and failure of surrounding rock is a process of sustainable development. The irregular fractures generated by unloading will continue to produce new ones, whose development law, in turn, affects the deformation and failure of surrounding rock. The intersection of fractures leads to the formation of fragments of different sizes. Therefore, it is of great significance to study the development and distribution law of fractures or fragments of surrounding rock with the action of rockbolts for understanding the mechanism of controlling the deformation of surrounding rock. Many mostly use the methods of numerical simulation and laboratory test to study the peak strength, residual strength, stress-strain relation, and deformation law of fractured specimens under different support modes of rockbolts, while the influence of rockbolts on the distribution law of fragments of fractured specimens is seldom studied [5-9].

The fractal method, which deals with the scaling of hierarchical and irregular systems, offers new opportunities for modeling the fragmentation process and is commonly used to study the distribution of fracture and fragments after the failure of surrounding rock $[10,11]$. For example, Badge, $\mathrm{Xu}, \mathrm{He}$, and Huang [12-15] used the method to analyze the degree of fragmentation of rock mass under blasting or impact loading and considered that the distribution of 
fragments conformed to the fractal law. Liu et al. [16] studied the relationship between the fragmentation of rock mass and fragments distribution through "Brazilian test" and field test and considered that the fragment fractal dimension and fracture fractal dimension conform to parabolic law. Fu et al. [17] quantitatively studied the roof with complex conditions in the gob and thought that the fractal characteristics of the roof essentially reflected the nonlinear characteristics of the gob boundary. Gao et al. [18] studied the relationship between damage variable and fractal dimension during deformation and failure of salt rock. Zhang et al. [19] studied the fragmentation and fractal characteristics of porous rocks with fractures by uniaxial compression tests and confirmed that the relationship between uniaxial compressive strength of rocks and fractal dimension is approximately positive.

This paper carried out the test of the support effect of rockbolts on fractured specimens by using the designed triaxial test system with physical similarity. The fractal method is more mature in the field of rock mechanics. It is used to analyze the distribution law of fractures and fragments and to research the support effect of rockbolts; the conclusion obtained has certain reference significance for understanding the mechanism of control deformation of rockbolts and guiding the stability control of roadway.

\section{Testing Device and Scheme}

2.1. Testing Device. A set of triaxial loading testing device, which can simulate the actual stress conditions in the field, was developed in order to study the support effect of rockbolts on rock mass. The size of the specimens contained in the device is $400 \mathrm{~mm} \times 400 \mathrm{~mm} \times 400 \mathrm{~mm}$. The constraints on the left and right sides of the specimen are realized by two steel plates, whose thicknesses are all $80 \mathrm{~mm}$ and connected by round steel rods of $\Phi 50 \mathrm{~mm}$. And the rear plate is made of steel plate of thickness $80 \mathrm{~mm}$, whose function is to restrain the backward displacement of the specimen by welding constraint plate separately on the left and right-side plate. The test device is shown in Figure 1.

\subsection{Similarity Relation of Simulated Test and Test Material.} Considering that the diameter of rockbolts and anchorage force are all small, using the model with a small similarity ratio is difficult to quantitatively study the evolution of fractures and the support effect of rockbolts on the fractured specimen, so a model with a large similarity ratio is adopted. According to the purpose of the test, the similarity ratios are determined, the geometric similarity ratio is $C_{1}=2$, and the real size of the surrounding rock in the rib simulated by the specimen is $800 \mathrm{~mm} \times 800 \mathrm{~mm} \times 800 \mathrm{~mm}$. The unit weight similarity ratio is $C_{\gamma}=1.4$. The stress similarity ratio is $C_{\sigma}=C_{\mathrm{l}} \cdot C_{\gamma}=2.8$, which is the same as the similarity ratios of modulus of elasticity, cohesion, and strength. The similarity ratio of the pretightening force is $C_{\mathrm{f}}=C_{1}^{3} \cdot C_{\gamma}=11.2$. The similarity ratios of Poisson's ratio, internal friction angle, and strain are all 1.0. The test rockbolt, on which the strain gauge is pasted to test its stress change, is made of $\Phi 8 \mathrm{~mm}$ HRB400 screw steel based on the similarity ratios. The pretightening force is applied to each specimen by applying a torque wrench. The face plates of rockbolts are made of round steel plate, whose diameter is $70 \mathrm{~mm}$ and thickness is $10 \mathrm{~mm}$. The physical and mechanical parameters of the model and surrounding rock are shown in Table 1 .

Cement mortar, which can simulate the surrounding rock more realistically, is a kind of heterogeneous material with similar mechanical properties and stable characteristics to rock mass [20]. The similar materials used in this paper are composed of quartz sand, cement, and gypsum by mixing with water according to a certain mass ratio. The mass ratio of quartz sand, cement, and gypsum is $75 \%: 10 \%$ : $15 \%$, while the weight of water accounts for $10 \%$ of solid mass. The size of the specimen is $400 \mathrm{~mm} \times 400 \mathrm{~mm} \times 400 \mathrm{~mm}$. When the material is fully stirred, it is poured into a mould, as shown in Figure 2.

2.3. Test Scheme and Process. The supporting resistance provided by rockbolts is not in the same order of magnitude as in situ stress and has little effect on the intact surrounding rock, while the supporting resistance has a certain effect on the fractured surrounding rock as it is in the same order of magnitude as the residual stress of fractured surrounding rock.

Surrounding rock is destroyed instantly by the release of its elastic energy after excavation and before rockbolting. The action target of rockbolts is the fractured surrounding rock located at the plastic zone. Therefore, the specimens need to be prefractured to simulate the fractured surrounding rock.

The vertical load of the specimen was exerted by YE-5000 hydraulic pressure testing machine, its lateral confining pressure was provided by the left and right baffles connected by tie rods, and its rear confining pressure was exerted by the rear baffle, while its front pressure was exerted by a Jack with a reaction frame, as shown in Figure 3.

Three-dimensional stress was applied to the specimen to simulate the in situ stress. When reaching the preset stress, the stress of the front baffle was unloaded while the vertical load was continuously loaded, the purpose of which is to simulate the unloading effect of excavation. When the specimen entered the postpeak stage, the loading was stopped, and the prefracturing of the specimens was completed.

The prefractured specimen was drilled. Then, the simulated rockbolts were installed and a pretension force of $5 \mathrm{kN}$ was applied to them by the torque wrench, as shown in Figure 4 .

A static strain tester was used to record the change of loads in the specimen, rockbolts, and tie rods during loading. The digital dial gauges were used to monitor and record the displacement, as shown in Figure 5.

In order to reduce the friction between the specimen and the test bench, the plastic film was used to wrap the specimen. The specimen was wrapped in plastic film in order to reduce the friction between the test piece and the test bench. The sizes of plastic the film are $400 \mathrm{~mm} \times 400 \mathrm{~mm}$ and $400 \mathrm{~mm} \times 3200 \mathrm{~mm}$, respectively. The $400 \mathrm{~mm} \times 400 \mathrm{~mm}$ 


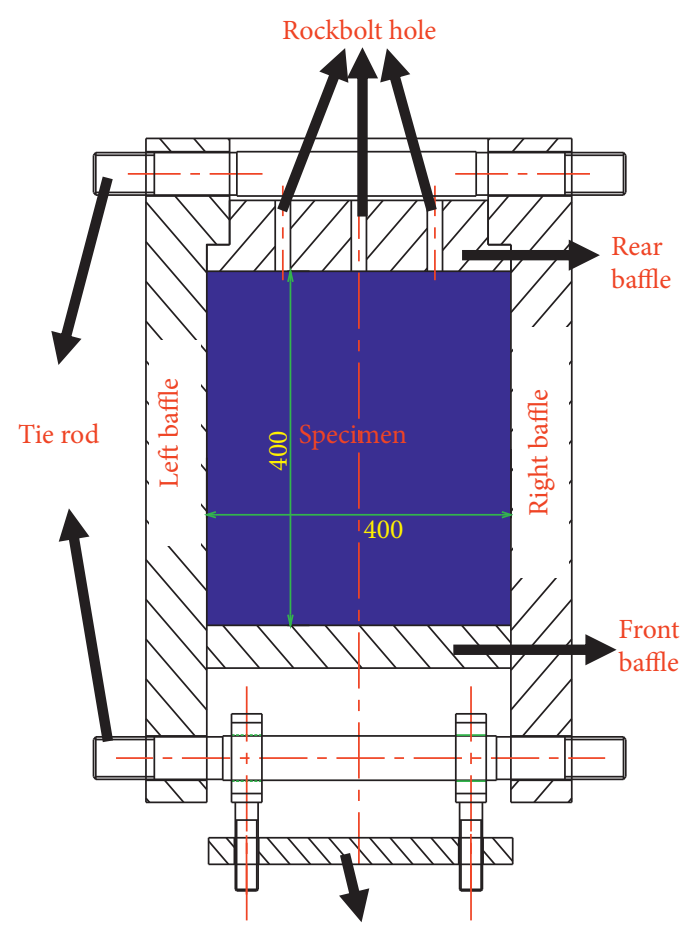

Reaction frame

(a)

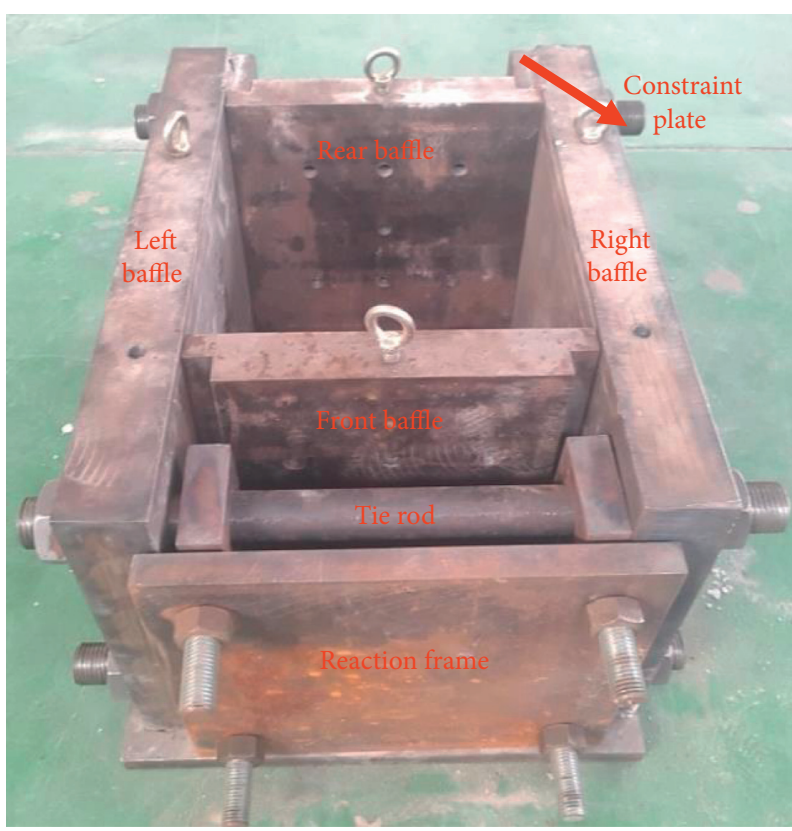

(b)

Figure 1: Testing device of model. (a) Sketch map. (b) Device object.

Table 1: Physical and mechanical parameters of the model.

\begin{tabular}{lccccc}
\hline Material & Bulk density $\left(\mathrm{g} \cdot \mathrm{cm}^{-3}\right)$ & Elasticity modulus $(\mathrm{GPa})$ & Poisson's ratio $(\mathrm{MPa})$ & Cohesion $(\mathrm{MPa})$ & Friction angle $\left(^{\circ}\right)$ \\
\hline Similar materials & 1.7 & 99 & 0.26 & 0.31 & 37 \\
Surrounding rock & 2.4 & 268.9 & 0.26 & 0.89 & 37 \\
\hline
\end{tabular}

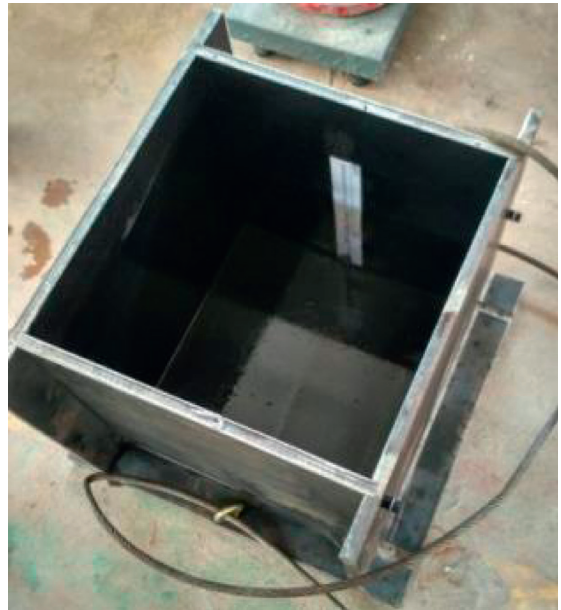

(a)

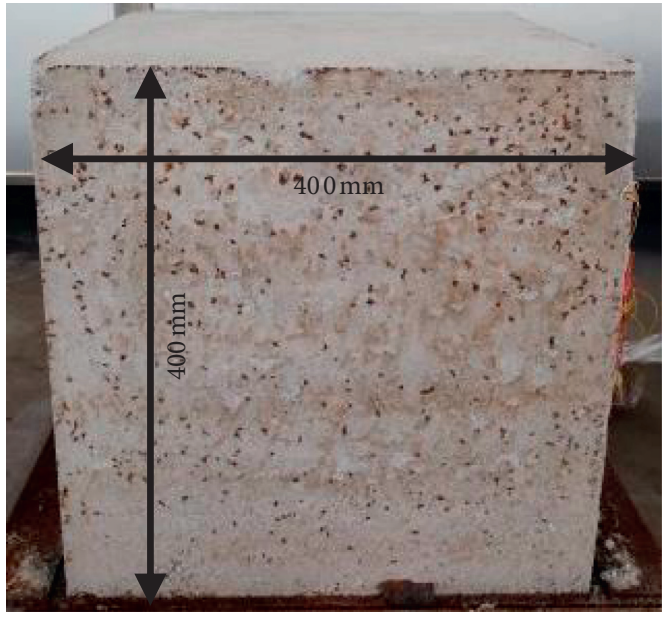

(b)

FIgUre 2: Specimen. (a) Specimen mould. (b) Specimen. 


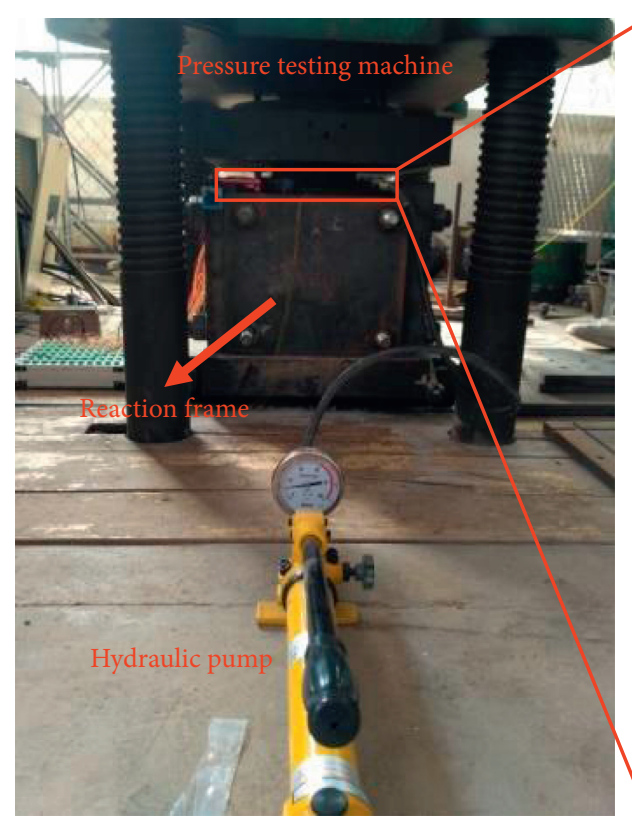

(a)

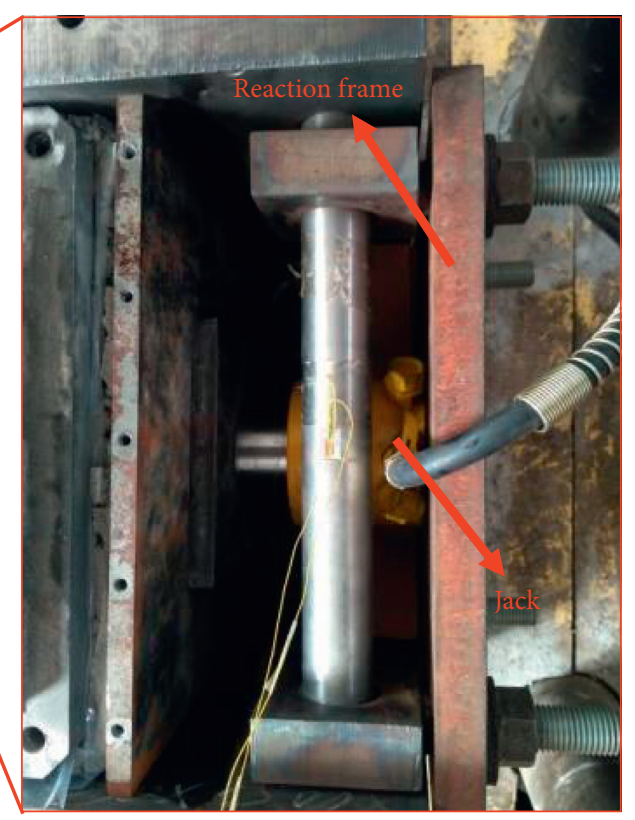

(b)

Figure 3: Schematic diagram of the reaction frame. (a) Front view. (b) Partial top view.

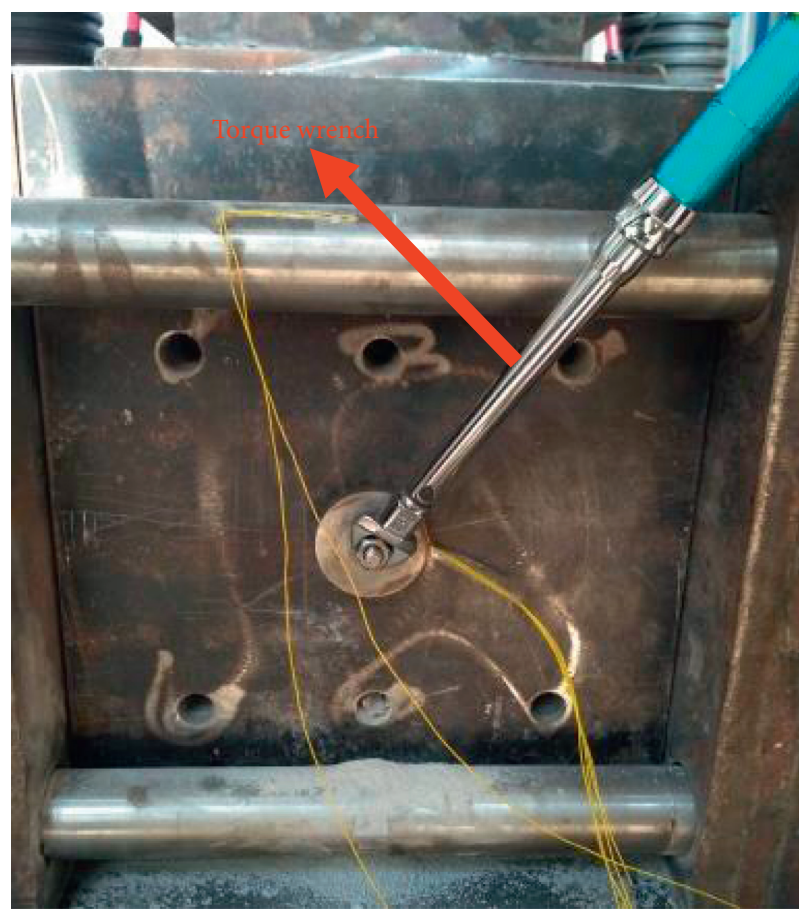

Figure 4: Apply pretension force.

film was placed at the bottom and top of the specimen to reduce the friction between the bottom of the specimen and base of the test bench and between the top of the specimen and the top plate of the test bench, while the $400 \mathrm{~mm} \times 3200 \mathrm{~mm}$ film was wrapped around the specimen to reduce the friction between the side of the specimen and the test bench, as shown in Figure 5.

In order to minimize the difference of the mechanical properties between the specimens, four specimens were

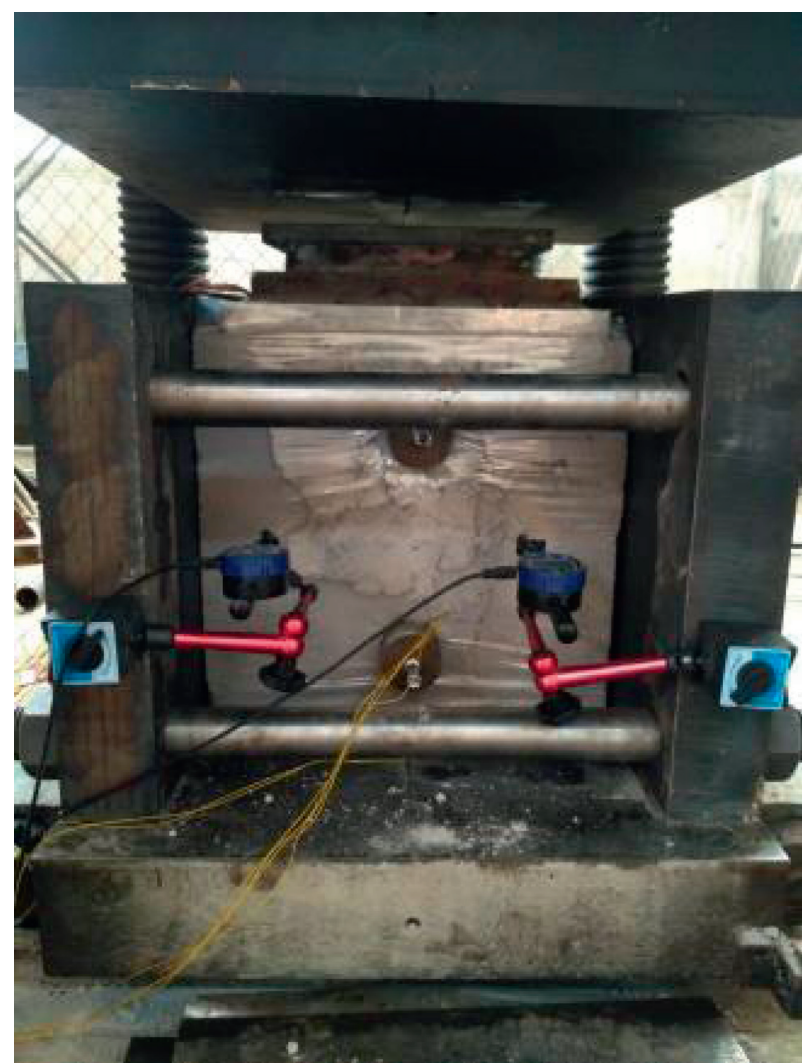

Figure 5: Model test bench.

pouring at one time by concrete mixer. Four different test conditions, including no rockbolt, one rockbolt, two rockbolts, and three rockbolts, were carried out to study the effect of rockbolts on postpeak fractured specimens. 


\section{Analysis of Test Results}

\subsection{Deformation and Failure of Specimens}

3.1.1. Stress-Strain Curve. The vertical stress and strain of the specimens during compression are shown in Figure 6.

It can be seen from Figure 7 that the peak strength of the specimens tends to be increased gradually with the increase of rockbolt density. For example, the peak strength increases from $1.5 \mathrm{MPa}$ to $2.18 \mathrm{MPa}$ as the number of rockbolts changes from one to two. The relationship between the number of rockbolts and the peak strength of specimen is shown in Figure 7. Nonlinear curve fit shows that the relationship between them satisfies an exponential function, and the fitting equation can be written as

$$
\sigma_{m}=-2.33 * \exp (-0.49 n)+2.94 \text {. }
$$

The correlation coefficient is $R^{2}=0.9986$, whose fitting correlation is high.

The stress-strain curve has a good yield platform, and the plastic flow phenomena occur in the postpeak range, even resulting in strain-hardening behavior, showing the approximate ideal elastic-plastic characteristics. The specimens can maintain a high bearing capacity while deforming.

With the increase of vertical load, the fragments formed by the fragmentation of the specimen will show a dilatation. The passive bearing force of rockbolts forms a higher constraint force to the specimen, which is equivalent to exerting a certain confining pressure on the specimen. The larger the number of rockbolts, the greater the equivalent confining pressure, in which case the peak strength of the specimen is increased and the deformation of the specimen is limited. The conclusions are consistent with the ones of the existing research [21].

3.1.2. Deformation and Failure Characteristics. The test results show that the failure modes of the specimens are different because of the difference of rockbolt density under the condition that the vertical displacements of the specimens are close to each other. Through the analysis of the test results shown in Figures 8 and 9, it is concluded that when the number of rockbolts is two, the displacement of specimen in the direction of bolt axis is smaller than that when the number of bolts is one, but the fragmentation of specimen is more serious and the average size of fragments is smaller. It can also be seen from the side fracture diagram of the specimen that when the number of bolts is one, the fracture gap of the specimen is larger and the displacement of fragments is larger.

The specimen under the action of load will undergo repeated failure from the complete state and finally fracturing into small fragments of different sizes. Firstly, the main fracture causes the specimen to break into larger fragments, which formed locally stable structures by inlaying each other. The structures will be unstable due to the overturn or movement of one of the fragments, in which the case leads to the secondary fragmentation of fragments. This

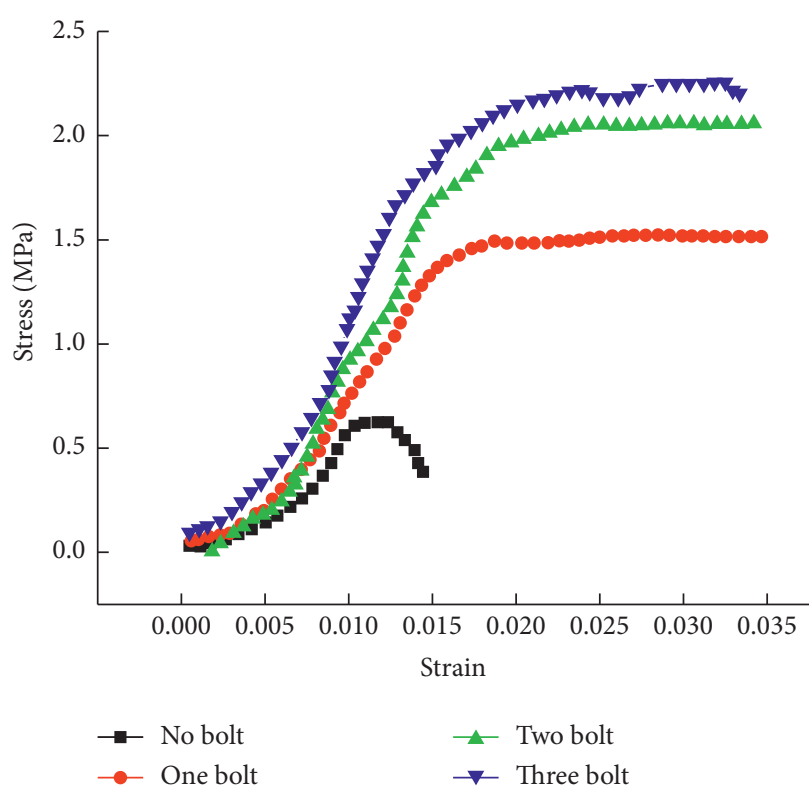

Figure 6: Stress-strain curve.

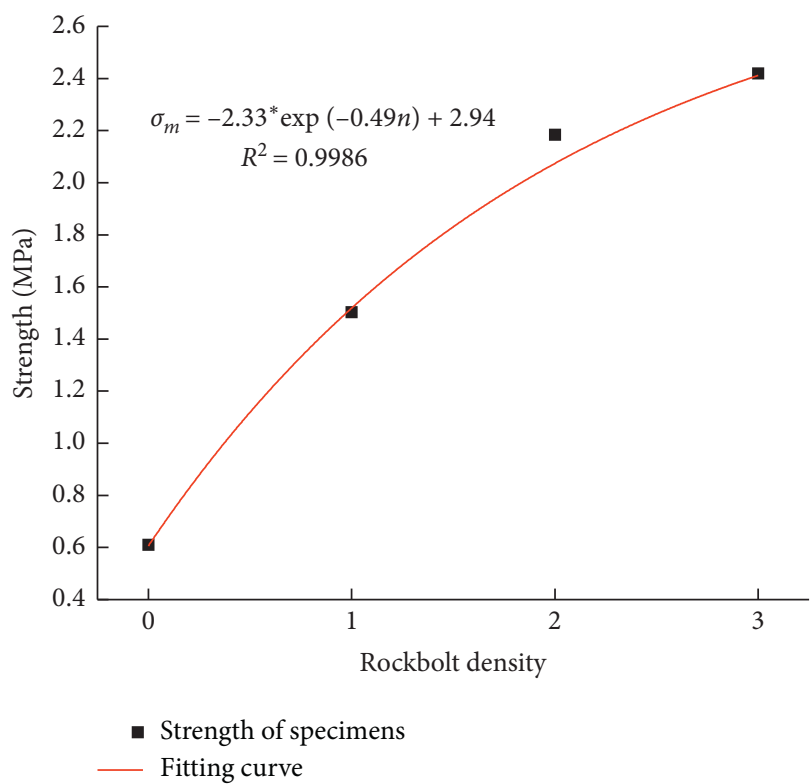

Figure 7: Relationship between rockbolt density and strength.

process of local stability-instability-restabilization will proceed periodically until the whole system reaches equilibrium. However, the case with a larger number of rockbolts is equivalent to applying greater confining pressure and, as a result, the peak strength of the specimen is larger and the probability of secondary fragmentation is greatly increased. Therefore, the specimens with a large number of rockbolts are severely fractured and the size of the fragments is small.

3.2. Fractal Study on Fracture of Anchored Specimens. The term fractal was first introduced by the mathematician Mandelbrot. It takes extremely irregular geometric figures as 


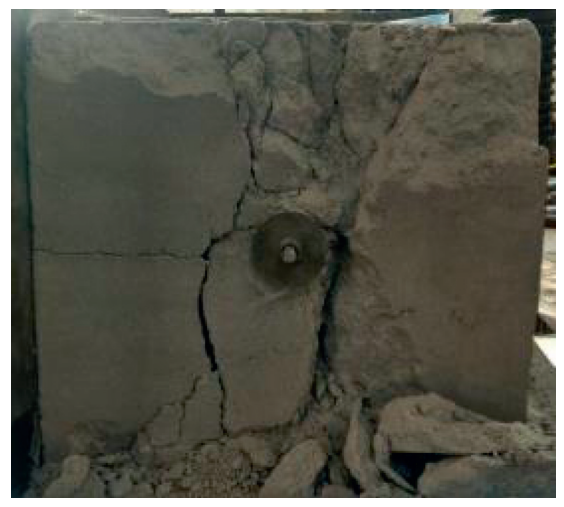

(a)

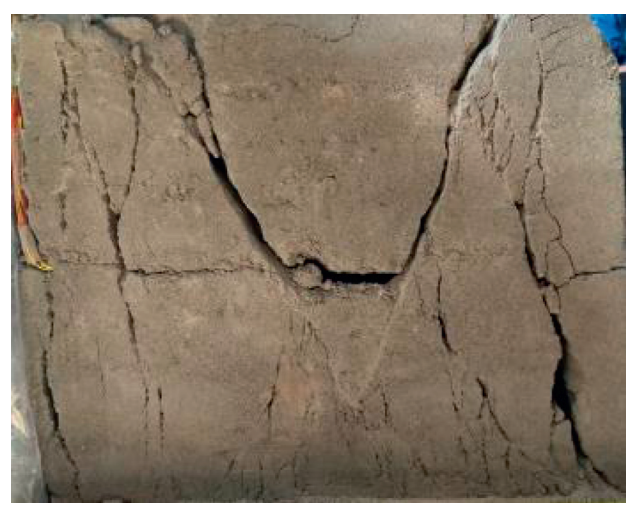

(b)

FIgURe 8: Diagram of fragmentation of one rockbolt. (a) Frontal destruction. (b) Side destruction.

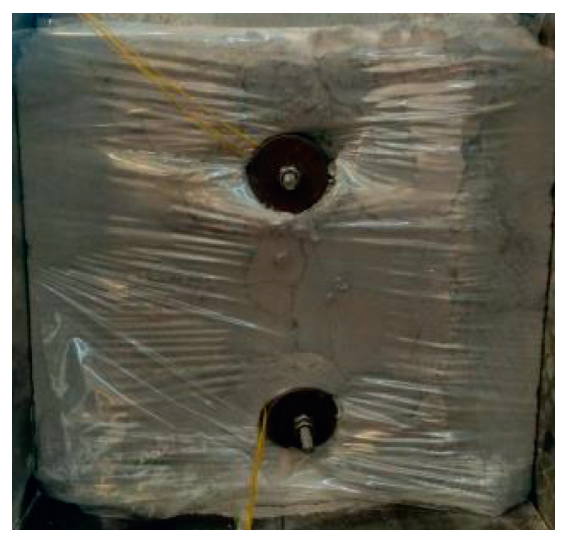

(a)

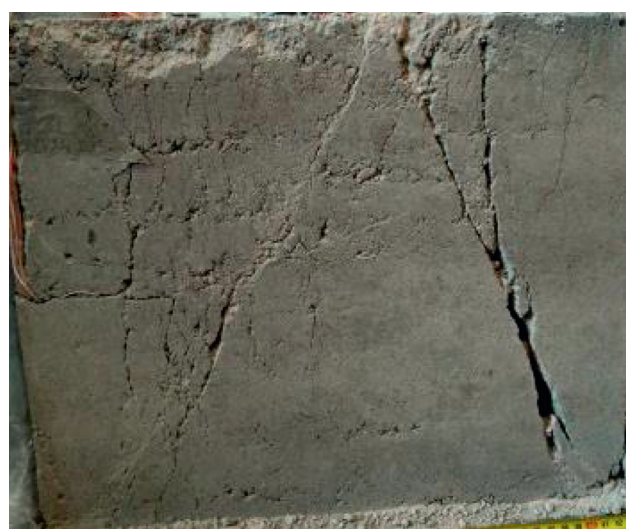

(b)

FIgURE 9: Diagram of fragmentation of two rockbolts. (a) Frontal destruction. (b) Side destruction.

the research object and quantitatively describes its complexity with fractal dimension. Under the loading of the testing machine, the specimens form a series of fractures, after which interconnection occures and fragments will be produced. The generation and evolution of these fractures have good self-similarity and fractal characteristics $[22,23]$.

The purpose of studying fracture fractal of rock mass is to explore the self-similarity law of the distribution of fracture at different scales and to characterize the degree of fracture development in order to obtain the relationship between fractures and rockbolting. Therefore, using fractal theory to describe the development law of fractures will play an important role in analyzing the rockbolting mechanism and rock failure mechanism and grasping the stability control mechanism of rockbolts to roadway.

Box counting is a method of sampling an image to find the rate of change in complexity with scale, as well as being often used in measuring the fractal dimension of rock fractures [24]. This method has the advantage of simple operation, and the fractal dimension measured can not only reflect the quantitative relationship of the distribution of fractures but also reflect the propagation and interconnectivity of the fractures, so it is more suitable for studying the evolution law of fractures.

The basic procedure is to systematically lay a series of grids $\left(\delta_{i} \times \delta_{i}\right)\left(\delta_{i+1} \times \delta_{i+1}\right)$ of decreasing calibre (the boxes) over a fracture image and record data (the counting) for each successive calibre. According to box counting theory, the following relationships between number $(N)$ and scale $(\delta)$ is given:

$$
\frac{N_{i+1}}{N_{i}}=\left(\frac{\delta_{i}}{\delta_{i+1}}\right)^{D},
$$

where $N_{i}$ and $N_{i+1}$ are the number of nonempty boxes.

Determining how number $(N)$ changes with scale $(\delta)$ by finding the slope of the logarithmic regression line for $N$ and $\delta$. The opposite number of the slope is the fractal dimension $D$; that is,

$$
D=-\lim _{\delta \longrightarrow 0} \frac{\log N(\delta)}{\log \delta} .
$$

Figure 10 is the fracture image of the specimen. The original image is of RGB type. However, the image needed 


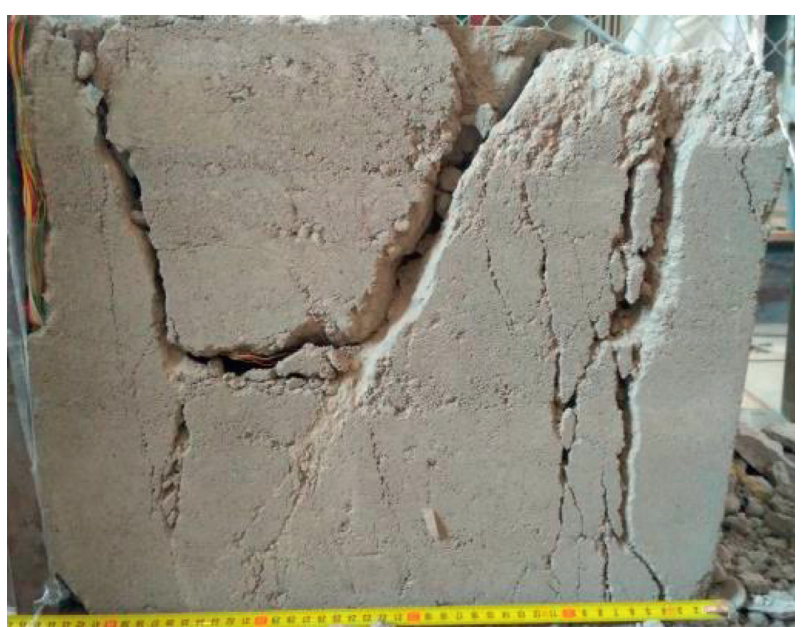

Figure 10: Original fracture image.

for fractal calculation is a binary image. Target fractures and background are segmented by the gray threshold segmentation method, and the gray image is binarized. The threshold function is as follows:

$$
g(x, y)= \begin{cases}0, & f(x, y)<T, \\ 1, & f(x, y)>T,\end{cases}
$$

where $g(x, y)$ is the binary value of the image, the value 0 represents black, the value 1 represents white, and $T$ is the threshold of image segmentation.

There are still some artifacts in the processed images, which are black spots. By removing the artifacts from the processed images, the binary image of the side fracture image of the specimen is obtained as shown in Figure 11, where black pixels represent fractures.

Using the above method, the fractal dimension of fracture images under different rockbolt density is calculated, as shown in Figure 12. The results show that the linear correlation is good and the correlation degree $R^{2}$ is greater than 0.9 , so the distribution of fractures of all specimens obeys the law of statistical fractal.

The surface fractal dimensions of the specimens with different rockbolt densities are shown in Table 2.

The fitting equation is given by

$$
D=1.54-0.172 * \exp (-0.607 n) .
$$

The fitting correlation coefficient is $R^{2}=0.998$, which means the surface fractal dimension of fractures has a good correlation with rockbolt density. Figure 13 shows that the surface fractal dimension increases with the increase of the rockbolt density. Fractal dimension reflects the development degree of the fracture network. The larger the fractal dimension, the worse the integrity of the specimen. In other words, the fractures are more developed, and the specimen is fractured more seriously. Therefore, the surface fractal dimension is an important index to comprehensively reflect the effect of rockbolting. From the fitting equation (5), with the increase of rockbolt density, the surface fractal dimension has an upper limit value, which is not always increasing.

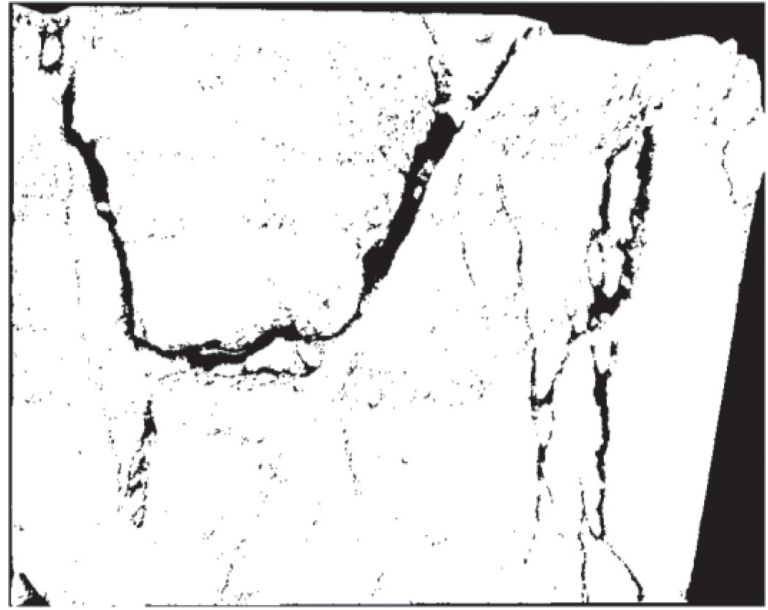

Figure 11: Processed image.

\subsection{Relationship between Fragmentation Fractal Dimension and Surface Fractal Dimension}

3.3.1. Fragmentation Fractal Dimension of the Specimen. Microstructure of rock mass shows that the pores and fractures in rock mass conform to the distribution law of fractal. And the fracture propagation causes the specimen to break into fragments. Fractal dimension, as a quantitative index reflecting complexity, can also be used to quantitatively describe the fragments distribution of specimens.

The fragments of the specimen are collected and measured its quality, length, width, and thickness, which are converted into the equivalent edge length $r$ of the cube. The fragmentation fractal dimension $D_{f}$ is calculated according to the size and quality of fragments. The formula is given by [14]

$$
\begin{gathered}
\frac{M(r)}{M_{0}}=\left(\frac{r}{r_{0}}\right)^{a}, \\
D_{f}=3-a,
\end{gathered}
$$

where $M_{0}$ is the total quality of fragments and $M(r)$ is the cumulative quality of fragments whose sizes are less than the equivalent edge length $r$.

According to formulas (6) (7), if the linear correlation in $\log \left(M(r) / M_{0}\right) \sim \log \left(r / r_{0}\right)$ double logarithmic coordinate system is good, there is a fractal law with statistical significance for the distribution of fragments. In the case, the slope of the regression line in the double logarithmic coordinate system is the value of $a$, according to which the fragmentation fractal dimension $D_{f}$ can be given. The result can be illustrated in Figure 14.

The scattered points of data in Figure 14 have a good linear correlation in the double logarithmic coordinate system. The fragmentation fractal dimension under different conditions obtained by the above method is shown in Table 3.

The relationship between fragmentation fractal dimension and rockbolt density is fitted, and the fitting curve is shown in Figure 15. 


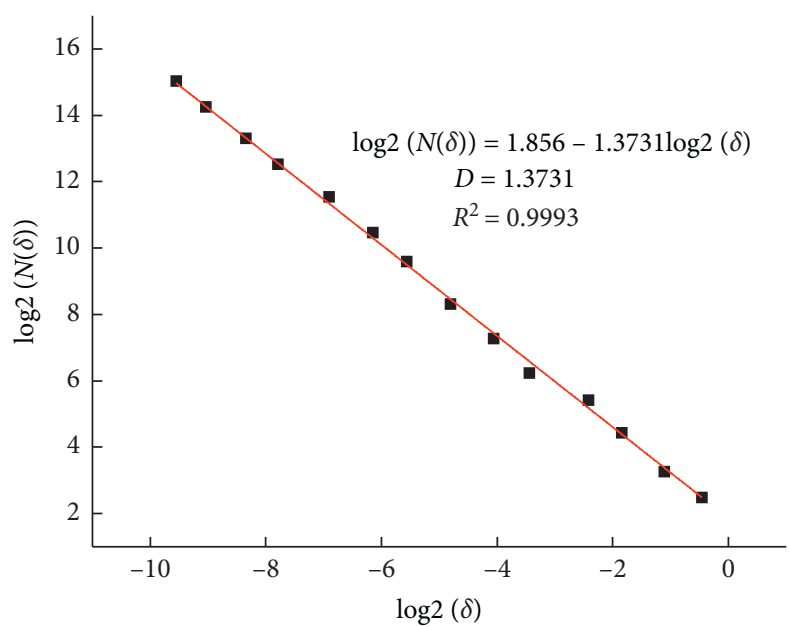

- Number of boxes (no rockbolt) - Fitting curve

(a)

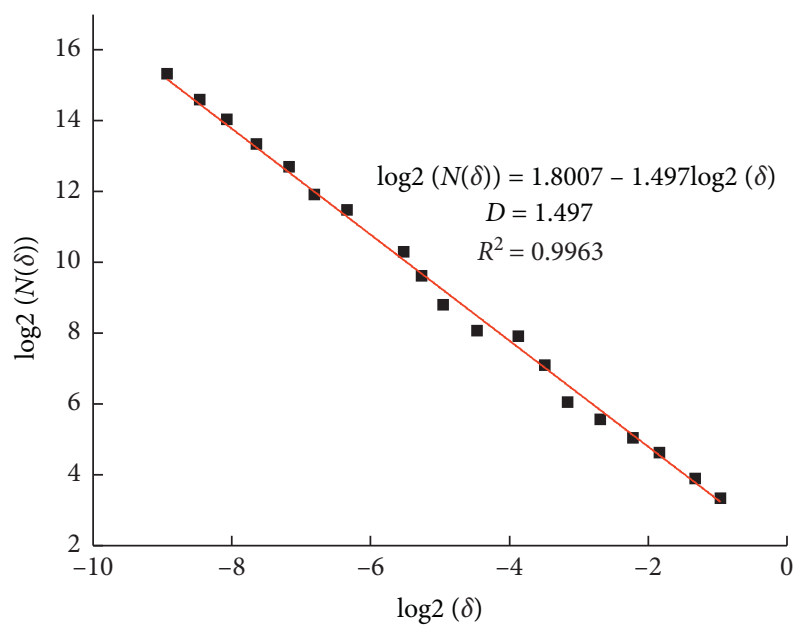

- Number of boxes (no rockbolt) Fitting curve

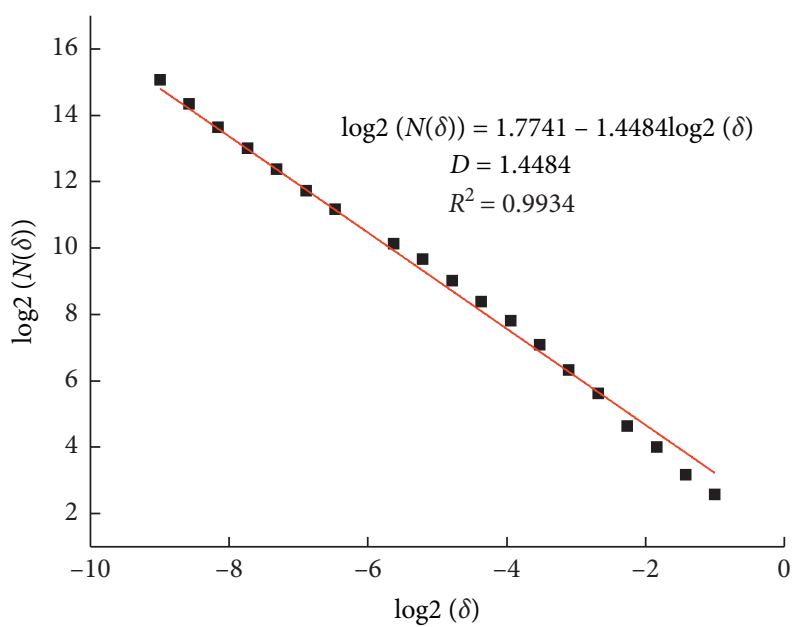

- Number of boxes (no rockbolt) Fitting curve

(b)

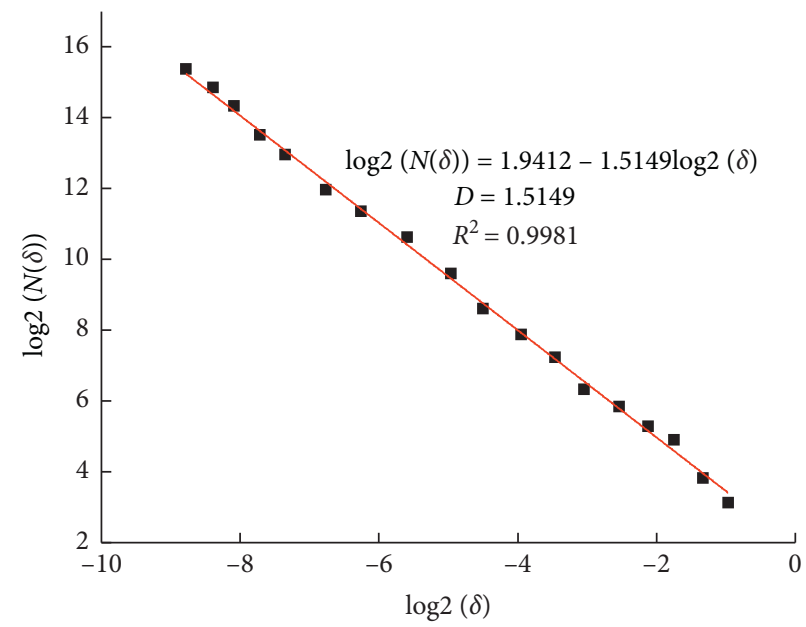

- Number of boxes (no rockbolt) Fitting curve

(c)

(d)

FIGURE 12: Log-transformed fragment number $(N)$-size $(\delta)$ distributions.

TABLe 2: Fractal dimension of fracture specimen.

\begin{tabular}{lcccc}
\hline Type & No rockbolt & One rockbolt & Two rockbolts & Three rockbolts \\
\hline Fractal dimension & 1.3731 & 1.4484 & 1.497 & 1.5149 \\
\hline
\end{tabular}

The fitting equation is given by

$$
D_{f}=2.56-0.3125 * e^{-0.533 n} \text {. }
$$

The correlation coefficient is $R^{2}=0.994$, which shows that it is in good agreement with the exponential function. Therefore, the fragmentation fractal dimension increases exponentially with the increase of rockbolt density, but its rate of increment decreases. In theory, the fragmentation fractal dimension of the specimen approaches a constant value when the rockbolt density reaches a certain value.
The relationship between rockbolt density and fragmentation fractal dimension generally obeys the exponential law, which can be given by

$$
D_{f}=A+B e^{C \cdot n}
$$

where $A$ is the maximum fragmentation fractal dimension and $B$ and $C$ are parameters related to the material of the specimen. It can be seen from formula (9) that the effect of the increase of rockbolt density on the increase of fractal dimension is limited. When the rockbolt density is small, the 


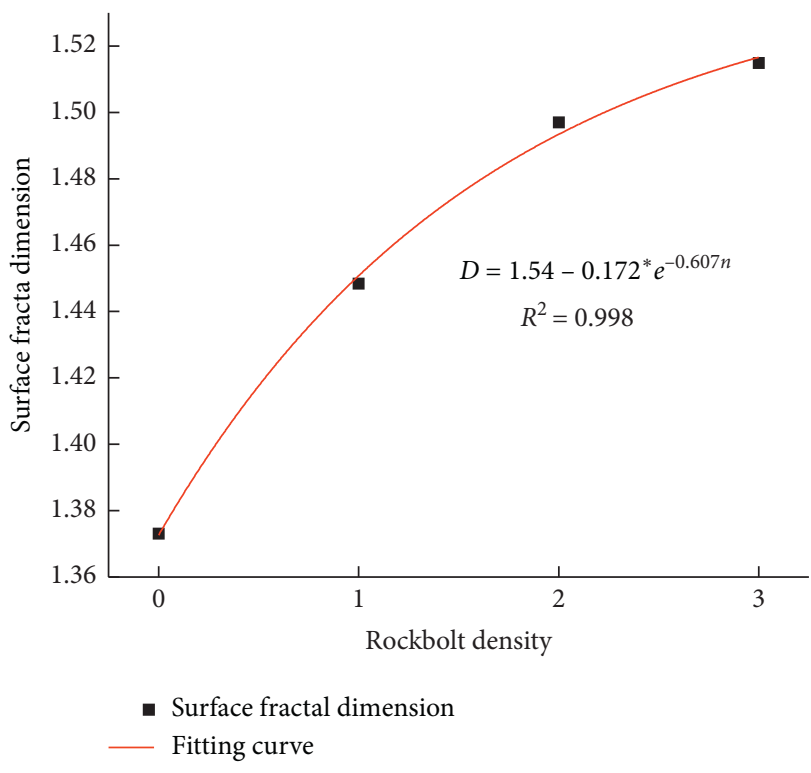

Figure 13: Scatter graph of fractal dimension of the fracture specimen.

fractal dimension decreases rapidly. When the density increases to a certain value, the fractal dimension tends to the maximum value $A$. Therefore, in practical engineering, it is unrealistic to increase rockbolt density blindly to increase fragmentation fractal dimension and to reduce porosity in the fractured surrounding rock, which will only result in the waste of manpower and materials.

However, as the current observation methods of fracture network of roadway are opaque, the fracture distribution law has been in a "black box" state. A few observation methods, such as nuclear magnetic resonance, $\mathrm{X}$-ray scanning, and synchrotron, can only observe the fractures of the smallsized specimen. Therefore, it is difficult to obtain the fragmentation fractal dimension in the interior of the roadway, but it can be researched indirectly by observing the fractures on the surface of the roadway or by observing the changes of fractures in the surrounding rock through drilling the borehole.

3.4. Relationship between Surface Fractal Dimension and Fragmentation Fractal Dimension. The surface of fracture is located in the interior of surrounding rock, and only the fractures on the roadway wall or exposed to borehole wall can be observed, through which the fractal dimension measured is the surface fractal dimension. As long as determining the relationship between surface fractal dimension and fragmentation fractal dimension, the fragmentation fractal dimension can be roughly estimated by surface fractal dimension and, as a result, the development of fractures and the distribution law of fragments size can be mastered.

Fracture fractal dimension is a description of fracture distribution. Fragmentation fractal dimension reflects the fragmentation degree of surrounding rock. They all reflect some physical mechanism to some extent. There should be a one-to-one correspondence between the fragmentation of surrounding rock and the distribution of fractures.

In Euclidean geometry, the intersection of three-dimensional objects on the cross section is a two-dimensional surface. This characteristic of dimension-reduced brings great convenience to the research of objects, whose internal and external changes have certain connections. In order to study the relationship between three-dimensional fractures and two-dimensional fractures, it is assumed that the specimen is a cube in which the distribution of fractures is isotropic; that is, the fragments are also cubes and uniform in three coordinate directions in space.

A cube is constructed and is illustrated in the simple schematic of Figure 16. The size of the cube is $L$. The size of the box is $\lambda$. The number of boxes divided equally on each side is $d=L / \lambda$. The number of boxes occupied by fractures in any measuring section is $N$. Then, the number of boxes in the whole cube is $N \cdot d$. The fractal dimension $D_{3}$ of fractures is given by

$$
D_{3}=\lim _{\lambda \longrightarrow 0} \frac{\ln (N \cdot d)}{-\ln \lambda}=\lim _{\lambda \longrightarrow 0} \frac{\ln N}{-\ln \lambda}+\lim _{\lambda \longrightarrow 0} \frac{\ln d}{-\ln \lambda},
$$

where $\lambda \longrightarrow 0,(1 / \lambda) \longrightarrow \infty$; then, formula (9) be written

$$
\begin{aligned}
D_{3} & =\lim _{\lambda \longrightarrow 0} \frac{\ln (N \cdot d)}{-\ln \lambda}=\lim _{\lambda \longrightarrow 0} \frac{\ln N}{-\ln \lambda}+1=D_{3} \\
& =\lim _{\lambda \longrightarrow 0} \frac{\ln (N \cdot d)}{-\ln \lambda}=D_{2}+1 .
\end{aligned}
$$

Formula (11) indicates that the difference value between the surface fractal dimension of two dimensions and fragmentation fractal dimension of three dimensions is 1 . The fracture fractal dimension of three-dimensional is equal to fragmentation fractal dimension under certain measurement conditions for fracture network of rock mass [10]. Therefore, the fracture fractal dimension of three-dimension can be obtained by the surface fractal dimension of the specimen, and then the fragmentation fractal dimension can be obtained.

The above conclusions are based on the idealized fractal model. In reality, the specimens belong to anisotropic material, its fractures are randomly distributed, and there are end effects. The surface fractal dimension for different sections is different, so the selection of the section has a great influence on the results. If the average values of multiple sections are used to calculate the fracture fractal dimension, a more accurate fractal dimension will be obtained.

The test results show that the relationship between the surface fractal dimension and fragmentation fractal dimension is shown in Table 4.

Table 4 shows that the difference value between the fragmentation fractal dimension and surface fractal dimension is not strictly equal to 1 , and the average difference is 0.9066 , as shown in Figure 17. The main factor may be that there is friction between the surface of the specimen and the baffles, which affect the development of fractures. The fractures on the surface of the specimen are not fully developed and the fractal dimension is small. At the same time, as the strength of the specimen is weakened by the boreholes 


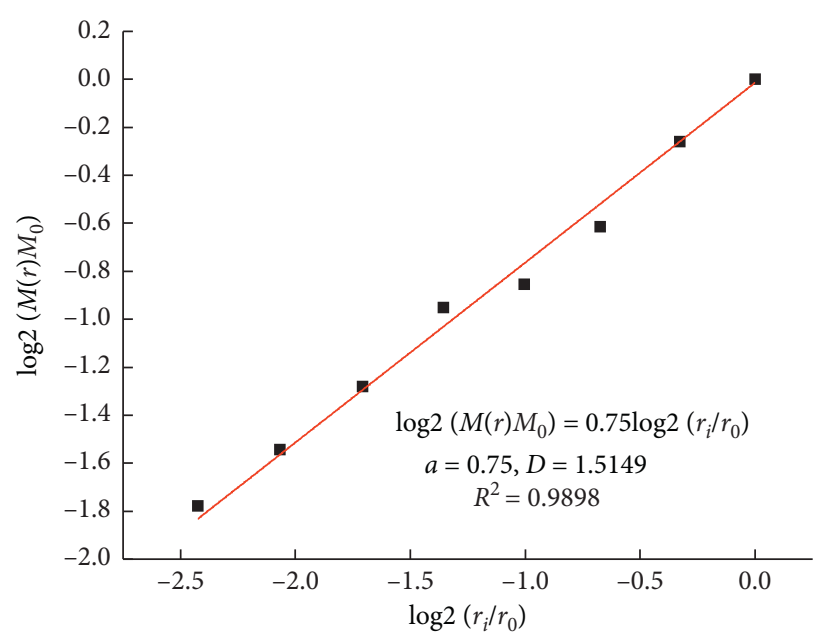

- Data (no rockbolt)

_ Fitting curve

(a)

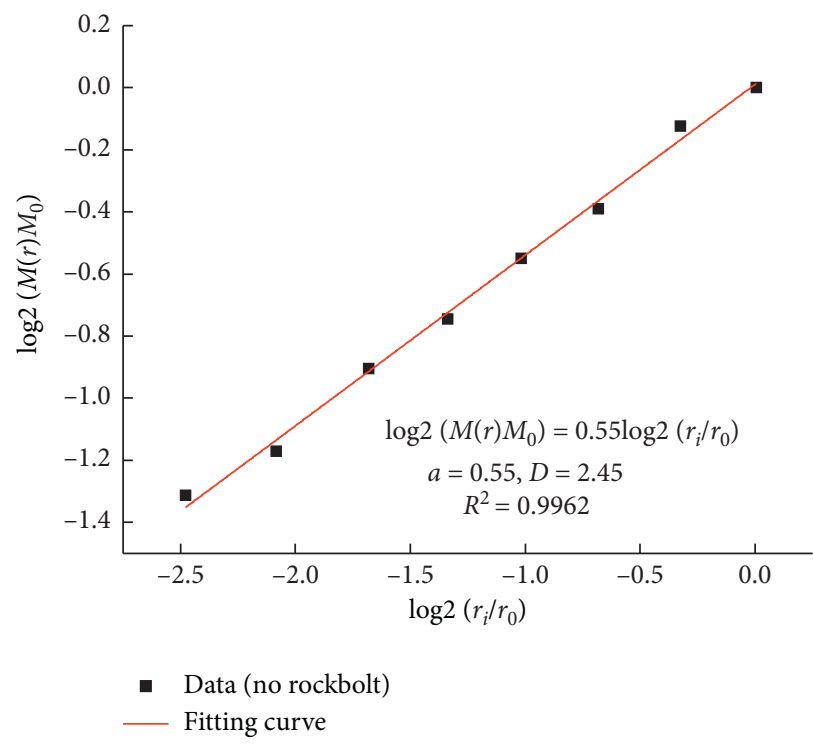

(c)

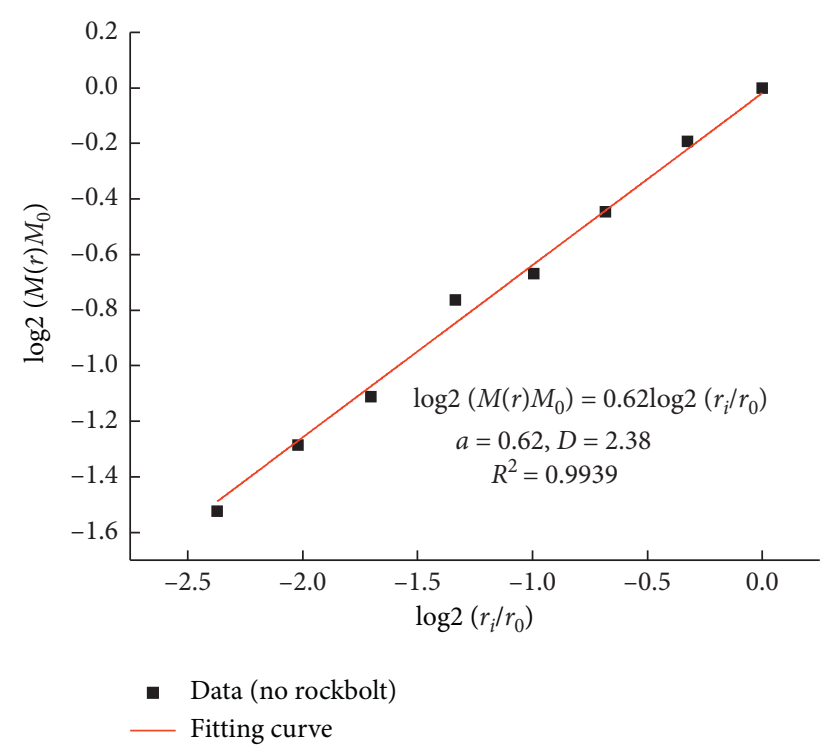

(b)

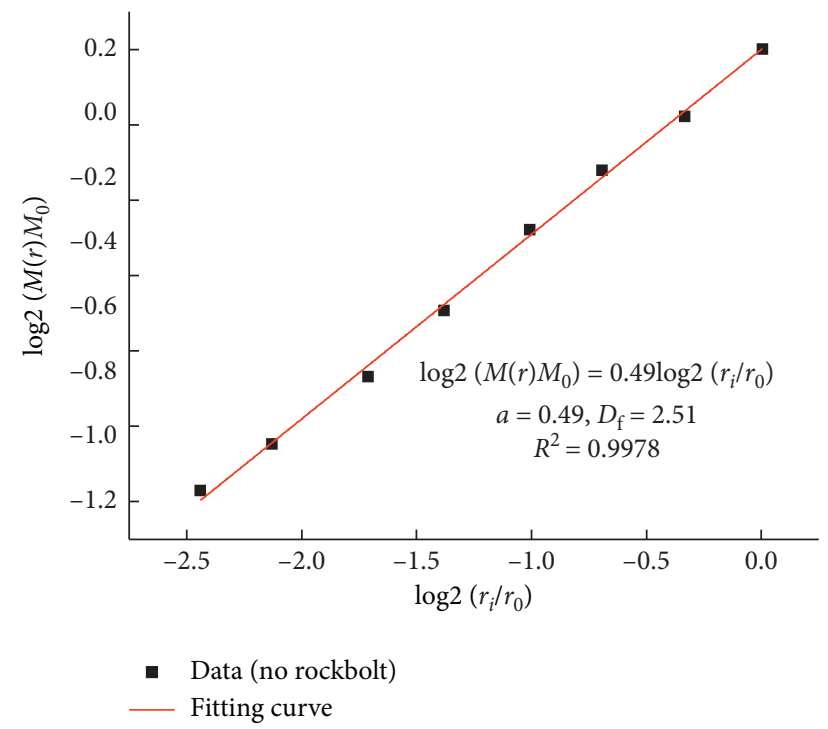

(d)

FIgURE 14: Geometric distribution of fragments.

TABle 3: Fragmentation fractal dimension.

\begin{tabular}{lcccc}
\hline Type & No rockbolt & One rockbolt & Two rockbolts & Three rockbolts \\
\hline Fractal dimension & 2.25 & 2.38 & 2.45 & 2.51 \\
\hline
\end{tabular}

for installing rockbolts, the stress concentration near the borehole occurs, tending to be easy to fracture. Therefore, the difference value between surface fractal dimension and fragmentation fractal dimension deviates from 1.

\section{Relationship between Displacement and Fractal Dimension}

The dilatancy of surrounding rock caused by friction, slip, rotation, and refragmentation between fragments is recognized as a major source of deformation of surrounding rock [21]. During the increase of depth of the plastic zone, the volume of surrounding rock in the plastic zone increases due to the dilatancy of fragments. In the deformation control of deep roadway, the support resistance provided by rockbolts, which cannot completely restrain the deformation of surrounding rock, is not the same order of magnitude as the in situ stress. However, smaller support resistance can improve the residual strength of surrounding rock in the plastic zone and reduce the deformation rate of surrounding 


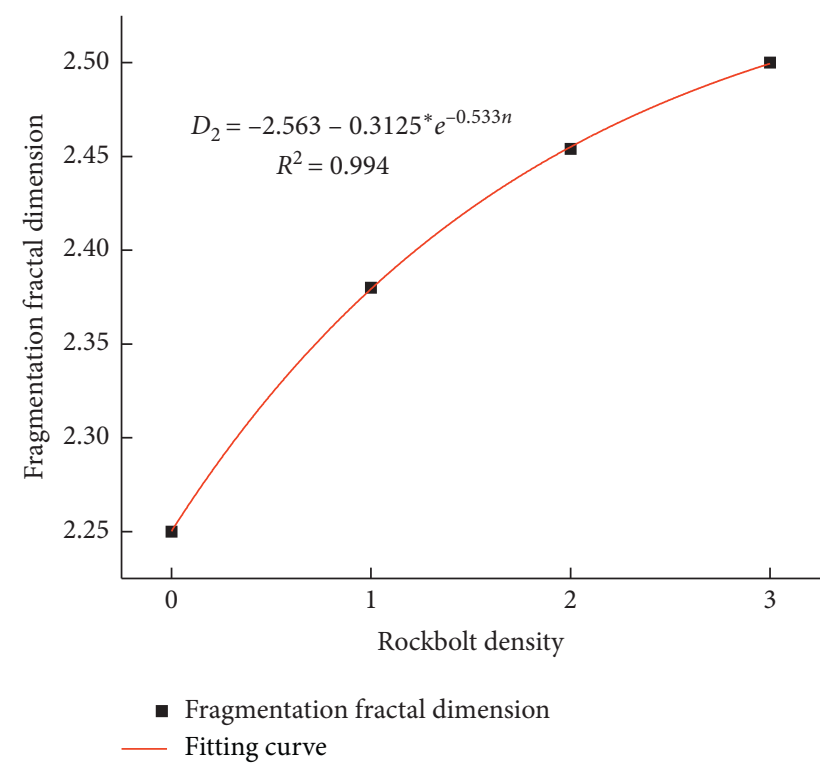

FIGURE 15: Fitting relationship between fragmentation fractal dimension and the number of rockbolts.

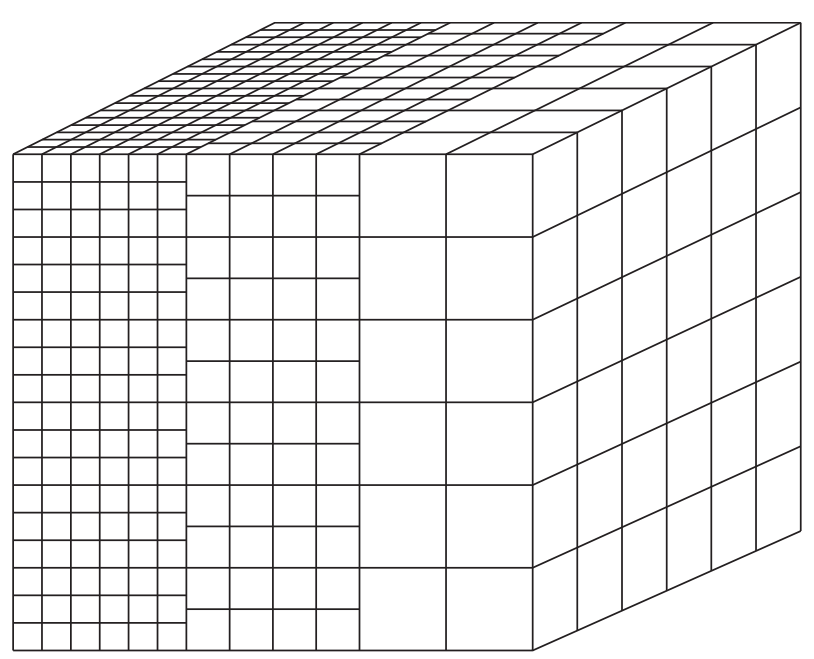

FIGURE 16: Schematic diagram of cube cut by fractures.

TABLE 4: Difference value of the fractal dimension.

\begin{tabular}{lccc}
\hline $\begin{array}{l}\text { Rockbolt } \\
\text { density }\end{array}$ & $\begin{array}{c}\text { Surface fractal } \\
\text { dimension }\end{array}$ & $\begin{array}{c}\text { Fragmentation } \\
\text { fractal dimension }\end{array}$ & $\begin{array}{c}\text { Difference } \\
\text { value }\end{array}$ \\
\hline 0 & 1.3731 & 2.25 & 0.8769 \\
1 & 1.4484 & 2.38 & 0.9316 \\
2 & 1.497 & 2.4541 & 0.9571 \\
3 & 1.5149 & 2.5 & 0.9851 \\
\hline
\end{tabular}

rock. Therefore, the volume of surrounding rock increases as a whole, and the deformation of surrounding rock will also increase $[25,26]$.

Fractal dimension reflects the degree of fragmentation of surrounding rock and to some extent also reflects some physical mechanism. According to the analysis of the test results, the fracturing process of surrounding rock is also an increasing process of fractal dimension. The more serious

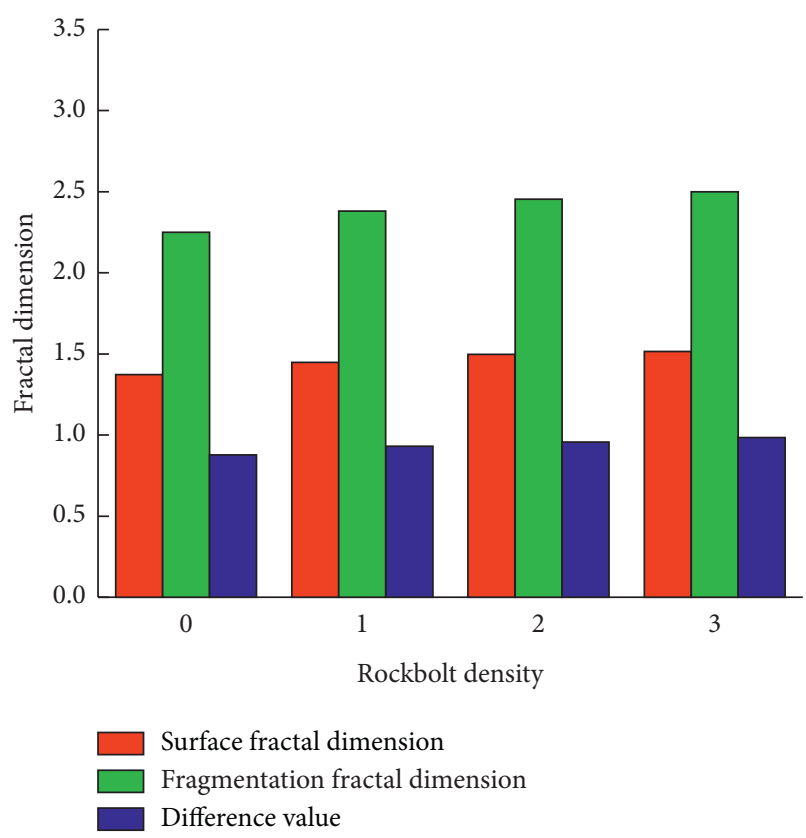

FIGURE 17: Relationship between surface fractal dimension and fragmentation fractal dimension.

the fragmentation of surrounding rock is, the more the fractal dimension increases. The fractal dimension can well represent the distribution of fractures. Therefore, the fragmentation fractal dimension has a certain correlation with its deformation. Their trends are the same, and there is a corresponding relationship between them. The fractal dimension can also reflect the deformation of surrounding rock and indirectly reflect the stability of roadway roof.

\section{Discussion on Anchorage Mechanism of Rockbolt}

Unit volume of the rock mass is fractured into fragments of different sizes, whose volume accumulated is related to its gradation. The fragments refractured several times will form an optimal gradation among themselves, while, at the same time, the accumulated volume is the smallest. From Apollonian Gasket [27], it can be also known that choosing an appropriate gradation can minimize the internal porosity, as shown in Figure 18.

Based on the research of deformation and failure law of specimens with rockbolts, it can be concluded that the mechanism of rockbolting is as follows.

The surrounding rock in the plastic zone without rockbolts is in a loose state. After the plastic zone is rockbolted, the anchorage zone is formed by adjusting the selfbearing capacity of surrounding rock. Friction and sliding between fragments along the surface of fractures is a structural effect. Fragments are geometrically incompatible with each other, in which case the fragments are extruded and embedded with each other. With the increase of the support resistance of rockbolts, the fragments are being squeezed more and more densely, and different structures 


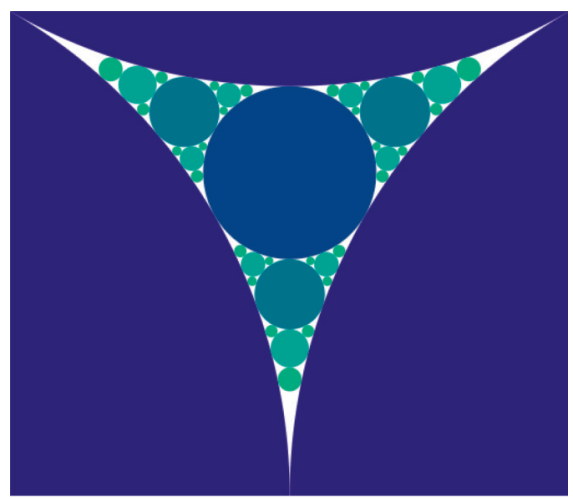

(a)

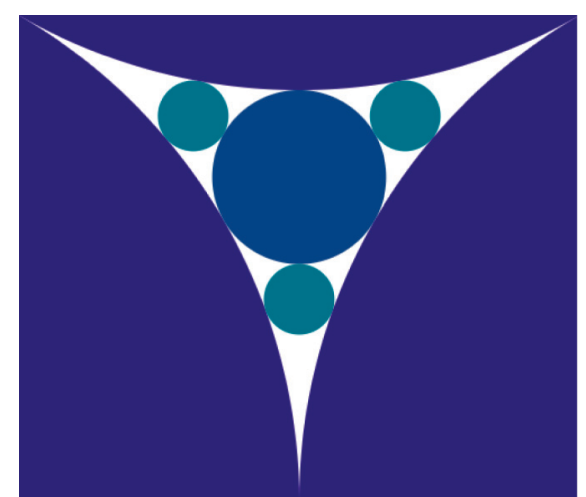

(b)

FIgURE 18: Schematic diagram of the Apollonian Gasket.

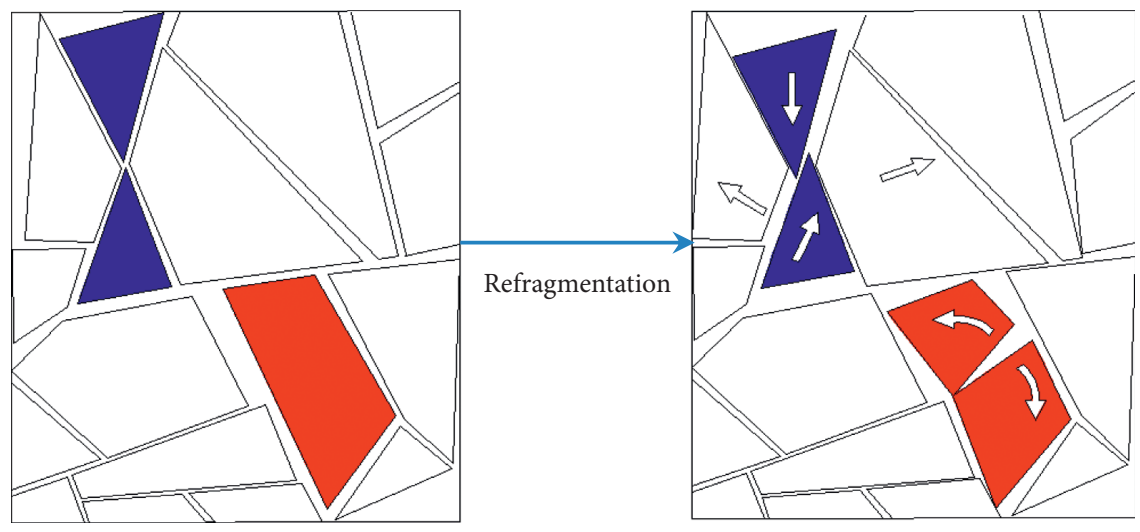

Figure 19: Schematic diagram of reragmentation of rock mass.

will be formed between them, such as the structure of a similar beam or arch.

At the same time, due to the meshing, rotation, and dislocation of fragments under the support resistance, the contact position between fragments may also form stress concentration in different degrees, after which to reach its strength limit, the structural instability and refragmentation will occur between fragments. Local stress in the plastic zone will be released and a new structure will be formed again with the deformation of surrounding rock. Such cycles of cyclical balance-instability-rebalance lead to more and more fragments and a smaller average size of fragments, as shown in Figure 19.

The space between large fragments is filled by small ones. The gradation of fragments is getting closer and closer to the optimal gradation. The growth rate of the volume of fractured surrounding rock is the smallest, and the deformation rate of surrounding rock is the lowest accordingly. In other words, the rockbolts restrict the velocity of surrounding rock movements to the roadway. At this time, the fractal dimension of fragments is larger and the degree of fragmentation is higher, which is consistent with the research conclusion of the previous test results. Therefore, the fractal dimension can be used as an index to evaluate the effect of rockbolting, to evaluate the stability of the roadway roof and to provide a reliable basis for rockbolting design.

The mechanism of rockbolting can be understood as follows: the anchorage is located in a stable elastic zone, rockbolts exert tension on rock mass located in elastic zone, and exert compression on rock mass located in the plastic zone. At the same time, the dilatancy force created in the expanding process of plastic zone also produces a compression effect on the rock mass of the original plastic zone, which increases the refragmentation probability of fragments combined with the effect of rockbolts.

The bigger the supporting resistance of the rockbolts is, the greater the probability of the refragmentation is, as a result, the fragments further breaks into subsize fragments, and the shape of the fragments develop towards that conducive to stability. And the distribution of fragments is close to the optimum gradation, in which case the porosity of surrounding rock in the plastic zone is the lowest. In other words, the effect of rockbolts is to reduce the porosity of surrounding rock in the process of fragmentation by increasing the probability of refragmentation and fractal dimension of fragments.

It should be pointed out that, due to the length of the paper, it mainly focuses on the comparison and analysis of different rockbolt densities but does not specifically analyze 
the different pretightening force, bolt with different materials, which needs further study. The research results have a good guidance and reference significance for the rockbolting design.

\section{Conclusion}

Through the analysis of the distribution law of fragments of specimens with rockbolts, some useful conclusions are obtained.

(1) The bearing capacity of the fractured specimens is positively correlated with the rockbolt density. With the increase of the rockbolt density, the bearing capacity of the fractured specimens increases gradually.

(2) The fracture fractal dimension and fragmentation fractal dimension both show growth of exponential law with the increase of rockbolt density. In theory, the difference value between them is 1 , but the difference value is approximately equal to 1 since some factors in practice. Therefore, by observing the fracture fractal dimension in a certain area of roadway, the fragmentation fractal dimension can be roughly obtained, and then the degree of fragmentation and size distribution of fragments can be obtained.

(3) The deformation of surrounding rock has the same trend with fragmentation fractal dimension. The larger the fragmentation fractal dimension, the larger the deformation of surrounding rock. Fracture fractal dimension of the roadway can be used as an index to evaluate the stability of roadway roof, which can provide some reference for rockbolting design.

(4) The rockbolting effect on surrounding rock increases the possibility of refragmentation of fragments, and the gradation of fragments is close to the optimal gradation which can minimize the porosity, thus reducing the deformation of surrounding rock.

(5) It is found that the more serious the degree of fragmentation of specimens is, the smaller the average size of the fragments is, and the more the number of fragments is. As a result, the fragmentation fractal dimension is also large. The higher the rockbolt density is, the larger the fractal dimension is. There is a positive correlation between the bolt support density and the fragmentation fractal dimension.

\section{Data Availability}

The data used to support the findings of this study are available from the corresponding author upon request.

\section{Conflicts of Interest}

The authors declare that they have no conflicts of interest.

\section{Acknowledgments}

This work was supported by the National Natural Science Foundation of China (Grant nos. 51874130, 51804109, 51974118, and 51774133).

\section{References}

[1] W. Wang, C. Yuan, W. Yu et al., "Stability control method of surrounding rock in deep roadway with large deformation," Journal of China Coal Society, vol. 41, no. 12, pp. 2921-2931, 2016.

[2] N. Ma, X. Zhao, Z. Zhao et al., "Stability analysis and control technology of mine roadway roof in deep mining," Journal of China Coal Society, vol. 40, no. 10, pp. 2287-2295, 2015.

[3] H. Kang, M. Fan, F. Gao et al., "Deformation and support of rock roadway at depth more than 1000 meters," Applied Sciences, vol. 34, no. 11, pp. 2227-2241, 2015.

[4] Z. Zhao, Mechanism of Surrounding Rock Deformation and Failure and Control Method Research in Large Deformation Mining Roadway, China University of Mining and Technology, Beijing, China, 2014.

[5] S. Niu, H. Jing, X. Yang et al., "Experimental study of strength degradation law of surrounding rock in fractured zone of deep roadway," Chinese Journal of Rock Menchaics and Engineering, vol. 31, no. 8, pp. 1587-1596, 2012.

[6] Y. Pu, Y. Xu, and J. Xue, "Model test of anchorage deep tunnel in blasting excavation," Journal of Engineering Science and Technology Review, vol. 35, no. 9, pp. 1830-1836, 2016.

[7] N. Liu, C. Zhang, and W. Chu, "Depth of fracture and damage in deep-buried surrounding rock and bolt length design," Chinese Journal of Rock Mechanics and Engine ering, vol. 34, no. 11, pp. 2278-2284, 2015.

[8] E. Dong, W. Wang, N. Ma et al., "Analysis of anchor spacetime effect and research of control technology considering creep of surrounding rock," Journal of the China Coal Society, vol. 43, no. 5, pp. 1238-1248, 2018.

[9] W. Zhu, H. Jing, L. Zhang et al., "Experimental study on the mechanical properties of lumpy rock mass under bolt reinforcement," Journal of Mining and Safety Engineering, vol. 35, no. 2, pp. 261-266, 2018.

[10] E. Perfect, "Fractal models for the fragmentation of rocks and soils: a review," Engineering Geology, vol. 48, no. 3-4, pp. 185-198, 1997.

[11] R. Zhang and L. Jing, "Analysis on the fragment and energy dissipation of deep sandstone after high/low temperature treatment in SHPB tests," Shock and Vibration, vol. 43, no. 7, pp. 1884-1892, 2018.

[12] M. N. Bagde, A. K. Raina, A. K. Chakraborty, and J. L. Jethwa, "Rock mass characterization by fractal dimension," Engineering Geology, vol. 63, no. 1-2, pp. 141-155, 2002.

[13] J. Xu and S. Liu, "Analysis of energy dissipation rule during deformation and fracture process of rock under high temperatures in SHPB Test," Shock and Vibration, vol. 32, no. S2, pp. 3109-3115, 2013.

[14] M. He, G. Yang, J. Miao et al., "Classification and research methods of rockburst experimental fragments," Chinese Journal of Rock Mechanics and Engineering, vol. 28, no. 8, pp. 1521-1529, 2009.

[15] D. Huang, Q. Tan, and R. Huang, "Fractal characteristics of fragmentation and correlation with energy of marble under unloading with high confining pressure," Advances in $\mathrm{Ma}$ terials Science and Engineering, vol. 31, no. 7, pp. 1379-1389, 2012. 
[16] H. Liu, Z. Zhao, S. Zhang et al., "Relationship between failure characteristics and fracture spacing of surrounding rock of short-distance coal seams group," Journal of China Coal Society, vol. 40, no. 4, pp. 766-773, 2015.

[17] J. Fu, W. Song, and Y. Tan, "Three dimensional fractal characteristics of complex roof of gob and its surface modelling," Journal of Central South University (Science and Technology), vol. 49, no. 2, pp. 431-438, 2018.

[18] X. Gao, J. Liu, T. Li et al., "Study of fractal and damage characteristic in the deformation and failure process of salt rack based on acoustic emission," Journal of Soil and Mechanics, vol. 39, no. 8, pp. 2905-2912, 2018.

[19] K. Zhang, X. Liu, K. Li et al., "Investigation on the correlation between mechanical characteristics and fracturing fractal dimension of rocks containing a hole and multi-flaws," Theoretical and Applied Fracture Mechanics, vol. 37, no. 12, pp. 2785-2794, 2018.

[20] E. Szcs, Similitude and Modelling, Elsevier Scientific Pub. Co., Amsterdam, Netherlands, 1980.

[21] X. Zhao, M. Cai, M. Cai et al., "Mutual influence between shear dilatation of rock mass and rebar support around underground excavation," Journal of Rock Mechanics and Geotechnical Engineering, vol. 29, no. 10, pp. 2056-2062, 2010.

[22] B. Mandelbrot, The Fractal Geometry of Nature, W. H. Freeman and Co., San Francisco, CA, USA, 1982.

[23] H. Nagahama, "Fractal fragment size distribution for brittle rocks," International Journal of Rock Mechanics and Mining Sciences \& Geomechanics Abstracts, vol. 30, no. 4, pp. 469-471, 1993.

[24] J. W. Crawford, B. D. Sleemant, and I. M. Young, "On the relation between number-size distributions and the fractal dimension of aggregates," Journal of Soil Science, vol. 44, no. 4, pp. 555-565, 1993.

[25] S. L. Crouch, "Experimental determination of volumetric strains in failed rock," International Journal of Rock Mechanics and Mining Sciences \& Geomechanics Abstracts, vol. 7, no. 6, pp. $589-603,1970$.

[26] A. Ord, "Deformation of rock: a pressure-sensitive, dilatant material," Pure and Applied Geophysics PAGEOPH, vol. 137, no. 4, pp. 337-366, 1991.

[27] B. Paul, "An introduction to the apollonian fractal," Computers \& Graphics, vol. 30, no. 1, pp. 134-136, 2006. 